\title{
Impact of nutrition counseling on knowledge, attitude and practice of pre-obese employees of University of Agricultural Sciences, Bengaluru
}

\author{
P. Siddarodha, B. Deshpande, D. Vijayalakshmi and M.T. Lakshminarayan
}

\begin{abstract}
The present study was carried out in Gandhi Krishi Vignana Kendra campus of UASB during 2016-2017 to know the efficacy of nutritional counseling on knowledge, attitude and practices of pre-obese employees of University of Agricultural Sciences, Bengaluru. A sample of 120 employees comprising both men and women (having BMI range from 25.0 - 29.9) in the age group of 35 to 55 years working in GKVK Campus of UASB were selected following purposive sampling method. The results of the study revealed a positive efficacy of nutrition counseling in improving the nutrition knowledge to bring favourable attitude towards optimum nutrition which can be translated into change in practices.
\end{abstract}

Key Words : Pre-obese, Impact, Nutrition counseling, Knowledge, Attitude, Practice

How to cite this article : Siddarodha, P., Deshpande, B., Vijayalakshmi, D. and Lakshminarayan, M.T. (2018). Impact of nutrition counseling on knowledge, attitude and practice of pre-obese employees of University of Agricultural Sciences, Bengaluru. Food Sci. Res. J., 9(2): 269-273, DOI : 10.15740/HAS/FSRJ/9.2/269-273. Copyright@ 2018: Hind Agri-Horticultural Society. 